\title{
Unease as a Feminist-Pragmatist Concept
}

Conceptualizing a Powerful Sentiment Along with Charlotte Perkins Gilman

\section{Katrin Wille}

\section{(2) OpenEdition}

1 Journals

\section{Electronic version}

URL: http://journals.openedition.org/ejpap/2103

DOI: $10.4000 /$ ejpap.2103

ISSN: 2036-4091

\section{Publisher}

Associazione Pragma

\section{Electronic reference}

Katrin Wille, «Unease as a Feminist-Pragmatist Concept », European Journal of Pragmatism and American Philosophy [Online], XII-2 | 2020, Online since 14 December 2020, connection on 15 December 2020. URL : http://journals.openedition.org/ejpap/2103 ; DOI : https://doi.org/10.4000/ ejpap. 2103

This text was automatically generated on 15 December 2020.

\section{(ब) $\odot \Theta$}

Author retains copyright and grants the European Journal of Pragmatism and American Philosophy right of first publication with the work simultaneously licensed under a Creative Commons AttributionNonCommercial-NoDerivatives 4.0 International License. 


\title{
Unease as a Feminist-Pragmatist Concept
}

\author{
Conceptualizing a Powerful Sentiment Along with Charlotte Perkins \\ Gilman
}

Katrin Wille

\section{AUTHOR'S NOTE}

I thank a reviewer of the article for helpful comments and Heidi Salaverría for inspiring discussions. We share the overall interest, to reevaluate negatively evaluated experiences. See her article "Vague Certainty, Violent Derealization, Imaginative Doubting. Reflections on Common Sense and Critique in Peirce and Butler" in this volume.

1 Democracy is a way of life that depends on dealing with unease. Unease is a diffuse negative sensation unlike articulated criticism of something or a rejection of something with reasons. Unease can indicate problems and difficulties that cannot yet be named as such or that cannot be expressed. Power relations may be at work as obstacles to articulation. Unease can be a feeling that has been imposed on certain groups that cannot participate in the democratic public in the same way as others. But unease can also be a form of dissatisfaction or fear of change. As such, unease can mobilize political forces. Uneasiness has very different manifestations and backgrounds and it is an important theoretical challenge to analyze and better understand the structure and varieties of unease.

2 For feminist theories, which are usually committed to a critical self-understanding, the feeling of unease related to gender relations is of great importance. Gender injustice like other forms of social injustice takes place on an obvious level as explicit devaluations and exclusions, but also on an implicit, hardly visible and only very diffusely felt level. The level of implicit injustice is in some ways the more difficult, persistent, tenacious one and deserves a great deal of attention. This is the case 
especially in our times and in the Western world, which is characterized by comparatively extensive formal equality of the sexes.

3 A closer examination of examples of diffuse unease help to point out the main features of this sentiment. Many examples can be found in feminist literature, such as the underlying impression of not being taken seriously or a latent insecurity in one's own thinking and speaking because of a diffusely felt inadequacy or obliqueness. In my analysis, the following four features are characteristic: First, the sentiment of unease has a negative-evaluative component. A situation is perceived as oppressive or uncomfortable or out of tune. Second, it is an unstable, hesitating evaluation without one's being able to assign what the sources or causes are and to what extent oneself or others are responsible. Third, this has to do with habitualized power asymmetries that attack the epistemic authority of some. Fourth, the affective and the somatic are closely connected and play a crucial role.

4 In this paper I would like to focus on a double layer in the conception of unease that is implied in the first and the third aspect. Unease is situational on the one hand and habitual on the other. It is a way of perceiving the (negative) qualities of a situation. But situations are always both singular as well as manifestations of more general habits and structures. Habitualized unease, which can be understood as something like a frustration that has become a habit, but also as an internalization of inferiority, can thus be easily actualized in certain situations. Habitualized unease is often a consequence of structural domination between sexes or racist structures. To unfold this double layer, I choose a pragmatist frame of reference. Pragmatist philosophers made important contributions to the functional role of habitualization and habits (Peirce, James and Dewey) as well as to the concept of a situation and the grasping of situations through their qualities (Dewey). But the phenomenal and conceptual complexity of unease needs more than these general concepts. They must be linked to experiences of unease and ways of concrete reflection on them. Therefore, it is systematically necessary to include theorists that offer both the close study of experiences of unease and a pragmatically informed conceptualization. Some of the early pragmatist female thinkers and writers such as Charlotte Perkins Gilman turn out to be a rich source for description and analysis. ${ }^{1}$ So there are both systematic and historical reasons to study the female pragmatists and benefit from their insights. Feminist pragmatism enables to place experiences like unease at the center and to unfold it philosophically. But the pragmatist conceptual frame has to be enriched and deepened by contributions from contemporary feminist theory for the sake of understanding this widespread but hardly ever specifically reflected sentiment. Important references for developing the features of unease are feminist Affect Studies, e.g. the work of Sara Ahmed (2017), as well as concepts of embodiment, as in the work of Iris Marion Young (1980) or Beate Krais (Dölling \& Krais 2017), who connects to Pierre Bourdieu's concept of habitus, or Miranda Fricker's (2007) concept of epistemic injustice. It is only through the systematic integration of these insights that it becomes possible to gain unease as a heuristic tool for the philosophy of pragmatism as well as for the concerns of feminism, and to transfer it to the manifold forms of discrimination in our daily life.

5 My argumentation is divided in two parts. In the first part, I present Charlotte Perkins Gilman as a phenomenologist of unease. In my suggested reading of her literary works, a dense description of unease comes into view, which reveals the mentioned features of 
unease. Two of her literary works seem particularly important to this approach. The story The Yellow Wallpaper (1892) can be read as a dynamic of increasing unease which ends in the erosion of epistemic authority. And the utopian novel Herland (1915) can be received as a staging of the social conditions of increasing unease through fictional inversion. She imagines a gynocentric normality in order to make normality visible and the emergence of unease observable.

In the second part a critical construction of unease as a feminist-pragmatist concept is suggested. Important insights into the social conditions of unease, which Perkins Gilman demonstrates in her work as a social theorist, such as The Man-Made World; or, Our Androcentric Culture (1911), are linked to the concepts of habit and quality in Dewey. Through qualities (in the Deweyan sense), ${ }^{2}$ one can grasp the meaningfulness and the affective coloring of a situation. This makes it possible to differentiate conceptually between situational and habitual unease and to relate them to each other.

\section{What Uneasiness Feels Like}

7 At the turn of the 19th and 20th centuries, the social theorist and literary figure Charlotte Perkins Gilman (1860-1935) searched for ways of articulation for the unease induced by the structural domination between the two sexes. Her unconditional plea for a primacy of practice suggests that she is a pragmatist thinker in a broad sense. This includes her concept of Humanity in the making; her commitment to a philosophy of practice that does not prioritize the category of being over that of doing, but vice versa; and the view that science is part of a democratic public. She understands her criticism of gender structures and of an androcentric world as a quest for democratic habits. A democracy must be a way of life and not just a political system. It is therefore necessary to scan all areas of society in search for undemocratic conventions and to put them at the center of criticism. A central object of her criticism is despotism in families. Perkins Gilman describes the American-European nuclear family as a "proprietary family," in which women not only live in economic dependence on men, but are themselves regarded as the property of men: "We live to-day in a democracy - the man-made family is a despotism." (Perkins Gilman 1911: 40). This critical interest leads her to analyze the interdependencies between economic structures, family dynamics, division of labour, dress norms etc. and, especially in her literary work, to describe expressions of habitualized unease of women.

8 Charlotte Perkins Gilman was a highly ambivalent theorist. ${ }^{3}$ On the one hand, she was an inspiring fighter for women's rights using the means of speech, literature, journalism and critical analysis. On the other hand, in her fight for this goal all means seem to be justified and she had a decidedly problematic preference for a population policy instrument of eugenics in which women were to play a decisive role as a kind of center for selection control. ${ }^{4}$ She is one of the many women in the so-called first wave of the women's movement, which does not address the structural similarities between different forms of injustice and suppression, but rather plays them off against each other. It is an important task of gender studies to analyze this problem in historically detailed reconstruction. ${ }^{5}$ The recognition of the structural connections between the axes of injustice is an important reason for the broad acceptance of "intersectionality" in gender studies over the past 20 years. Intersectional gender studies advocate the analysis of the interplay between different forms of injustice. Non- or even anti- 
intersectional feminist analyses are certainly not convincing today as theoretical frameworks. However, I do not believe that this makes it impossible to benefit from strong arguments and subtle insights. These must be contextualized and reframed in a feminist outline, that takes responsibility for the entanglement between different forms of suppression in a more general perspective.

9 I would therefore like to focus on one dimension of Perkins Gilman's work as a systematic contribution to the feminist-pragmatist concept of unease. Indeed, in my opinion, one source of the enduring inspiration of her texts lies in the way she expresses and analyzes the unease of the women of her time. She builds up the term, "androcentric world," to explain the social conditions that make widespread unease possible and sustain it. "Unease" is not part of her theoretical vocabulary (unlike "androcentric," "gynocentric"). However, the term can be used to grasp an important dimension of her work, and it shows the richness of insights that can be gained for this conception.

Perkins Gilman, as a writer, social theorist and political activist, uses three ways of expressing the unease of women in her time and initiating change. At first she depicts the dynamics of unease in literature, and second, as a social theorist, she analyzes the structures that facilitate and stabilize it and designs other economic and social models. Third, as an activist, she wants to open women's eyes to their situation and show them possibilities of change. The story The Yellow Wallpaper (1892) is particularly important for exploring the appearances of habitual unease. Many of her literary texts are more closely tied to her theoretical analyses and models and partly come out as mere applications of her theoretical ideas. One of her central interests is the analysis of the economic structures for the material dependency of women on men and the demand for economic independence. She realized this by the means of literature in What Diantha Did (1909/10) and theoretically in the widely discussed study: Women and Economics: A Study of the Economic Relation Between Men and Women as a Factor in Social Evolution (1898), which was translated into seven languages. Another main emphasis of her work is the critical analysis of androcentric reality, a reality which conflates humanity with masculinity. In fiction, she dealt with this topic in the utopian novel Herland (1915). There she sketches a gynocentric utopia to make androcentric normality appear ex negativo. Her theoretical argument is developed in her book The Man-Made World; or, Our Androcentric Culture (1911), in which she coined the term "androcentrism." I refer to her theoretical arguments in the second part of my paper.

The best-known and aesthetically most convincing story is The Yellow Wallpaper (1892). It provides also a rich source for the overt and subtle dynamics of gendered unease. The short story is written from the perspective of a young woman who, in order to alleviate her psychological suffering, has to submit under the medical prescription of a rest cure on the countryside. She is told to dwell in the former children's room of a rented house, which is furnished with yellow wallpaper. Her husband, who is also her doctor, decrees fresh air and extensive rest in this room. The chosen passage is placed at the beginning of the story. It opens up the unfolding interaction between the young woman and the yellow wallpaper in the children's room. For what remains to her in the enforced lack of social and intellectual stimulation is the immersion in the abundant design of the yellow wallpaper, which takes on step by step a life of its own. Through a mixture of fascination and threat, this wallpaper's life of its own gradually becomes the world in which the young woman lives, thinks and feels. The end of the story is like a 
final immersion into the world of the yellow wallpaper, which means from the husband's perspective the wife going mad. The historical background for this story is the "rest cure" developed by the specialist for nervous diseases, S. Weir Mitchell (1829-1914), in Philadelphia. Charlotte Perkins Gilman was subjected to this therapeutic measure for "hysterical" (middle-class) women in the spring of 1887, which included infantilization of the patients, bed rest, fatty food and prohibition of mental activity such as reading. ${ }^{6}$

12 I now turn to the text by Perkins Gilman and analyze it below from the perspective indicated:

John is a physician, and perhaps - (I would not say it to a living soul, of course, but this is dead paper and a great relief to my mind) - perhaps that is one reason I do not get well faster.

You see, he does not believe I am sick!

And what can one do?

If a physician of high standing, and one's own husband, assures friends and relatives that there is really nothing the matter with one but temporary nervous depression - a slight hysterical tendency - what is one to do?

My brother is also a physician, and also of high standing, and he says the same thing.

So I take phosphates or phosphites - whichever it is, and tonics, and journeys, and air, and exercise, and am absoluteley forbidden to "work" until I am well again.

Personally, I disagree with their ideas.

Personally, I believe that congenial work, with excitement and change, would do me good.

But what is one to do?

I did write for a while in spite of them; but it does exhaust me a good deal - having

to be so sly about is, or else meet with heavy opposition. (Perkins Gilman 1999: 230)

To what extent is this passage an expression of unease? Unease is a diffuse sensation, its origins remain unclear or are so varied and diverse that they cannot be clearly attributed. The sensation of unease includes being involved, entangled or even trapped in dependencies and determinations, which can be felt on a subcutaneous level. Unease has an evaluative component, something is felt as unpleasant, as oppressive and oppressing and somehow wrong. But the very structure and the conditions, that trigger the sensation are sustained and co-generated by one's own behaviour and thus somehow accepted. In the composition of the passage, this is emphasized by the question, asked three times, "What can one do?," or "What is one to do?"

The protagonist is not believed to be sick. It is a difficult communicative situation when a person's state of mind or state of health is not believed by a counterpart. This creates an asymmetrical relation in which the person who is not believed is forced into a defensive position. An imbalance of power emerges. If the person who has been put on the defensive bears with this communicative asymmetry and thus also acknowledges it in a certain way, unease arises. Unease turns out to be a state of ambivalence. The defensive situation oppresses and burdens that person, but the moment of acknowledging this asymmetrical situation weakens the capacity to take an active role and leads to resignation. It remains the rhetorical question: And what can one do?

Increasingly, the protagonist is confronted with two men of authority through their function in the family (as husband and brother) and through their professional position (both "highly respected" doctors). By virtue of their authority, both give the same medical diagnosis by classifying and explaining the condition of the person as experts. 
Thus the situation is unambiguous and determined, there is no room left for participation of a non-expert, even if the person's own condition and experience are concerned. The protagonist is deprived of first-person-authority with respect to her interior life. There is no way left to express her unease in the language of men, husbands, male relatives and doctors. The imbalance of power becomes an impossibility of expression, a withdrawal of language and even of any kind of power. The question comes out to touch a much more fundamental level of existence: "- what is one to do?"

The next step of aggravation consists in the shaping of conduct: the prohibition of certain activities, namely working, i.e. writing, reading, and the instruction of other activities such as going for a walk, getting some fresh air. This is intended to eliminate the possible sources or amplifiers of the imaginary illness, which is supposed to be any kind of mental work like reading or writing. But as it is described here, mental work is what the protagonist is interested in, what she regards as her talent and her mission. Mental work would enable her to express herself. Instead of this, an imposed practice of distraction should take place. The personal "I" of the protagonist has become placeless, inactive, unrelated. She is urged to an inaudible protest: "Personally, I disagree with their ideas." The question is raised for a third time: "But what is one to do?"

The three-part structure performs the increasing unease. Unease emerges at first due to the produced imbalance of power. Second, unease is intensified by the withdrawal of first-person-authority. Third, unease reflects the restriction of any freedom to act. The protagonist suggests two ways of dealing with this. One, which she has abandoned, consists in a combination of rebellion and secrecy. The associated effort to experience rejection and open criticism or to develop a system of secrecy proves to be unsustainable. The other is to make the illness persist ("perhaps that is one reason I do not get well faster"), which means a mixture of resistance and submission under the regime of deprivation. Perkins Gilman pictures in the progress of the story a third way. Unease becomes independent of shared reality. Step by step she withdraws from the world in which she cannot express herself and is not understood. Instead she gives life to the yellow wallpaper, immersing herself completely in the interaction with the yellow wallpaper. Her behaviour becomes incomprehensible to her social environment and is regarded as going crazy.

18 As a theorist, Perkins Gilmans wants to show that these dynamics of unease are generated and stabilized by the androcentric structure of our reality. "Androcentric" is a world in which the masculine is considered as general and is made invisible as a special gender amongst others. It is a consequence of such a structure that all those to whom the masculine is not ascribed and who are therefore forced to see themselves as deviating from the norm develop a disposition to the feeling of unease. For the asymmetry that characterizes this structure is an imbalance of power between two unequal positions. One position is that of the standard, from which the other position can be marked as gender. The marked position gets marked, but cannot mark for its part. This structure is maintained by the fact that both positions form a selfunderstanding, a behaviour, a body scheme and an affectivity in accordance with the ability to mark or to get marked. For those, who are at the position of getting marked, the disposition to feel unease pervades these different modes. This disposition to feel unease can manifest itself in many different ways and one can focus more on the social 
interactions, on the somatic level or on the psychic life. In The Yellow Wallpaper Perkins Gilman emphasizes the latter and portrays a possible way of psychic decomposition.

There is an inherent difficulty in making androcentric structures and their effects visible, since the accepted forms of articulation are designed from the perspective of those whose gender is neutralized. How can one uncover the perspectivity of a claimed neutrality, which is per definition a non-perspective, but rather the normal way to see things? Which forms of articulation are comprehensible and can be connected to shared forms of life? Perkins Gilman's novel Herland (1915) can be seen as an attempt to uncover this logic of neutralization and generalization. She chooses an indirect way and sketches the fiction of a gynocentric world in order to show the functional mechanisms of the androcentric one. Herland can also be read as an utopian novel, which seems like a simple reversal of gender power relations and an idealization of the feminine. This is not my question here.

The plot of the story is the following: Three men are travelling with a mixture of the spirit of adventure, of discovery and of conquest in little-known territories. More or less per accident they happen upon an area situated on a completely isolated high plateau. They find themselves in the middle of a civilization, that has grown over 2000 years on its own, consisting only of women. New generations emerge through a complex process of unisex reproduction (parthogenesis). The three men react very differently. The protagonist, named Van, from whose perspective the story is told, is conceived as a theoretical mind. He looks at this very different world through theoretical curiosity. He observes, asks questions and analyzes, and tries to understand this world in contrast to his own. The invention of this figure turns the novel Herland into a double-barreled narrative and theoretical text. The other two men are designed contrapuntally: Terry embodies the male conqueror, who is not willing and able to engage in this world and in the end has to leave this world because of an outbreak of violence. Jeff embodies the sensitive artist who, full of admiration for this world, develops the desire to become part of it and stays ultimately there.

21 I now quote a passage from the last third of the novel in which the protagonist Van reflects on the structure and effect of this world:

In missing men we three visitors had naturally missed the larger part of life, and had unconsciously assumed that they must miss it too. It took me a long time to realize - Terry never did realize - how little it meant to them. When we say men, man, manly, manhood, and all the other masculine derivatives, we have in the background of our minds a huge vague crowded picture of the world and all its activities. To grow up and "be a man," to "act like a man" - the meaning and connotation is wide indeed. That vast background is full of marching columns of men, of changing lines of men, of long processions of men; of men steering their ships into new seas, exploring unknown mountains, breaking horses, herding cattle, ploughing and sowing and reaping, toiling at the forge and furnace, digging in the mine, building roads and bridges and high cathedrals, managing great businesses, teaching in all the colleges, preaching in all the churches; of men everywhere, doing everything: "the world."

And when we say Women, we think Female - the sex.

But to these women, in the unbroken sweep of this two-thousand-year-old feminine civilization, the word woman called up all that big background, so far as they had gone in social development; and the word man meant to them only male - the sex. of course we could tell them that in our world men did everything; but that did not alter the background of their minds. That man, "the male," did all these things was to them a statement, making no more change in the point of view than was made in 
ours when we first faced the astounding fact - to us - that in Herland women were "the world."

We had been living there more than a year. We had learned their limited history, with its straight, smooth, upreaching lines, reaching higher and going faster up to the smooth comfort of their present life. We had learned a little of their psychology, a much wider field than the history, but here we could not follow so readily. We were now well used to seeing women not as females but as people; people of all sorts, doing every kind of work. (Perkins Gilman 1999: 195)

What is "the world" in the protagonist's country of origin (in the novel the United States of America at the beginning of the 20th century) is very different from what is "the world" in Herland. The world is shaped through a multitude of activities like certain movements of bodies, certain designs of the environment, certain ways of producing objects and dealing with them, and certain models of the self. One very limited area of the world is connected with gender through specific functions. In the world of the protagonist, these functions of the marked female gender are reproducing, caring and pleasing. In the world of Herland, men are this gendered group to which he himself belongs. He thus experiences for the first time this process of being special, of standing out from the general, and can reflect on it from a gender perspective.

The words "male," "man" have a background of many activities. These words are virtually charged with these activities and get their semantic richness from them. The spectrum of these activities is very wide and outlines the whole area of public and active life of the former American society, like: Marching, driving ships, climbing mountains, taming horses, waging war, conquering, cultivating nature, building, trading, teaching, researching, making people believe - everything that generates a world. While using the words "male," "man" this plenitude of images appears as a semantic horizon. These images are so manifold, that they represent nearly everything. Masculinity is not defined by gender-specific characteristics, such as strong, courageous, but by activities that are world-productive.

Perkins Gilman uses a kind of pragmatist theory of meaning here, according to which linguistic meaning is built up from a background of activities and the history of these activities. The meaning of the words "masculine," "man" is determined by activities that seem to be specific on the one hand, but on the other hand are self-generalizing, self-confirming and self-entitling. By contrast, the meaning of the words "feminine" and "woman" is determined primarily by the attribution to specific activities which are guided be the functions for the "masculine general."

The protagonist Van realizes this in his attempt to understand the new world in contrast to his familiar world:

These women [...] were strikingly deficient in what we call "femininity." This led me very promptly to the conviction that those "feminine charms" we are so fond of are not feminine at all, but mere reflected masculinity - developed to please us because they had to please us, and in no way essential to the real fulfillment of their great process. (Perkins Gilman 1999: 104)

The protagonist recognizes the androcentric structure of his world, its realization through conduct and activities and the meaning of the words male and female. Decisive reason is the experience of the gynocentric world with its own long history and its own habits and traditions. This history of activities gives the words their (vague) background. The meaning of words is not only formed by a long history of activities and habits, but this history is the meaning of words in the form of a vague horizon. Horizons are always broad and vague and never clearly defined because a (semantical) 
horizon figures as background against which individual uses of words can be understood. The androcentric structure is therefore also reflected in the meaning of words. The horizon of the words "man" and "masculine" has been formed by a great variety of world-producing activities. Words without a broad horizon of activity and history, in contrast, are "flat" and reduced in their possible uses.

If it becomes possible in Herland to regard women not as women but as human beings, this is because of the diversity of the world-producing activities that women carry out. Within the wide range of activities and interests, the activities of giving birth and caring play a central role. ${ }^{7}$

In the novel, the character of the protagonist Van in Herland also reflects another form of unease as the habitualized unease, which is well-developed in The Yellow Wallpaper and analyzed in the reflective parts of Herland. Despite of his curiosity the protagonist Van experiences unease time and again. The character Terry judges Herland consistently from the usual American androcentric structures and articulates open criticism and wants to offer resistance. In his opinion, gender relations like those in Herland should not exist, they are abnormal. He makes a break for it and eventually even uses violence by attempting rape. The character Jeff completely adapts to this world. But the protagonist Van feels unease because his habitual "background of his mind," in which he holds a position of power by sex, comes into friction with a new "background of his mind" in which he is deprived of it. His curiosity and interest in this world leads him not to go into a counter-position and open criticism like Terry, but to experience the friction of two irreconcilable worlds. Unease arises from a connection to both, to a world in which he belongs to those who have the ability to mark others, as well as to the world in which he belongs to the ones being marked. The sensation of unease hardly appears in his attitude as a theorist, but rather in his interactions with the citizens of Herland. It emerges especially in his sexual desires towards the woman with whom he entered into a relationship towards the end of the story. Their practice of sexuality, which has been created and cultivated through the 2000 year old way of life of unisex reproduction, and its effect in the newly entered relationship creates unease despite all interest and theoretical recognition.

In my reading, the work of Perkins Gilman is a rich source for describing what unease feels like. Moreover, her work can also been read as theorizing unease as a feministpragmatist concept. In the next section I would like to differentiate between two important forms of unease and develop their conceptual structure. Gilman's descriptions and analyses offer many clues to illuminate both forms, habitualized unease and situational unease, in their manifestations and conditions of origin. In the following section I will therefore repeatedly refer back to Perkins Gilman.

\section{Unease as a Critical Concept}

Both forms of unease, the habitualized and the situational unease, are not independent of each other, because habitualized unease is also varied and maintained in situations. In addition, there can be transitions between the internalization of inferiority, and the diffuse evaluative feeling that something is wrong with the conditions and interactions in a situation. In the former case the evaluative component of unease refers to the person herself (in the sense of: something is wrong with me, I am not sufficent). For theorizing the concept of unease, therefore, a terminology is needed that takes into 
account both forms in their difference and in their possible transitions. In pragmatist thinking two important concepts can be found for this purpose. Habitualized unease can be defined as a kind of habit with the pragmatist concept of habit. And the situational unease can be analyzed with the pragmatic concept of qualities. Through qualities the meaningfulness and the affective coloring of a situation are transmitted. The literary and theoretical works of Perkins Gilman show the necessity of including a power-critical and economic dimension. This brings into view the interaction between social conditions and types of "uneasy" situations that take place again and again.

The theorization, that will be presented in this section, is important in order to relate the concept of unease to other forms of power asymmetries and to expand the exclusive focus on gender relations that Perkins Gilman undertakes. Habitualized unease is the consequence of every structure through which a normality and a marked, subordinated other are generated. Habitualized unease is therefore also an important factor in the critical analysis of racist societies. ${ }^{8}$

Habits are social functions and not individual routines. ${ }^{9}$ Rather, habits develop from interactions between a social as well as material environment and people. Dewey opens his study Human Nature and Conduct from 1922 with the section "Habits as social functions" and makes clear how the idea of interaction is to be sharpened. The social and material environment includes systems of interrelations between individuals that shape people's needs and desires. Dewey mentions needs and desires such as demand for food, for houses, for a mate, for some one to talk to and to listen to one talk, for control of others. Customs regulate which types of needs are legitimate and which are not; how needs can and cannot be satisfied with regard to which type of resources and objects. Dewey holds this interweaving of sociality and materiality as "objective conditions" to which habits always refer and relate. These objective conditions of the environment are embodied in habits and act as predispositions to ways or modes of response, which have an inherent projective force of habit. Habits are therefore characterized through a tendency to repeat, continue and preserve. Habits become so naturally, a kind of second nature, that they act more like controlling and organizing forces in the background. In this sense, habits always include a kind of mechanization and automatization, almost by itself. As social functions, habits are results of complex processes of mediation. But their mode of action is immediate. They express themselves through intuitions, instinctive reactions and spontaneous feelings. They give direction to behaviour and perception. Habits manifest themselves in visible actions, but also in some subdued subordinate form. The latter shows up in selfrelations, expectations, affective structures, moods, postures and body sensations. Habits are therefore omnipresent, sometimes more obvious, sometimes more covert. They differ in this respect from dispositions that tend to make one think of something potential that needs actualization. Habits in this conception are in a double sense places of power in human life and behaviour. On the one hand, objective power structures are reflected in habits, on the other hand, habits have an effect on the behaviour of individuals like invisible power and control centers. But nevertheless, habits are not deterministic, there remains a constitutive latitude for change. Dewey therefore distinguishes two types of habits. The first is a type of habit with a strong tendency towards self-sustaining repetition. This type of habit is nearly totally a mechanical routine. The second is a type of habit which remains open to change. Dewey 
calls these intelligent or artistic habits. Repetition and change do not form a contrast here.

31 Perkins Gilman provides an important theoretical contribution to habitualized unease as a critical concept. In the following, I will therefore relate her analyses to Dewey's concept of habit and propose perspectives for generalization.

Habitualized unease or unease as habit is a social function. Therefore, social and material conditions must be included, through which modes of action and reaction are generated. Perkins Gilman draws attention to relationships of economic dependency and domination. She analyzes their effects on social interaction and self-relations. Economic dependencies are asymmetries of power and are reflected in political and micropolitical structures and interactions, primarily between those who have power over others and those over whom power is exercised. Perkins Gilman focuses on the "proprietary family." It is the institutionalization of economic dependencies between genders and generations and is maintained through appropriate habits. ${ }^{10}$ There are on the one hand those who provide the material basis, who do paid work and thus earn the money that gives the whole family housing, food, participation in cultural life. They form a different habit than those on the other hand, whose material existence depends on someone else. Due to the material superiority the first hold entitlements towards the persons dependent on them. These entitlements have the character of property relations.

This is exactly what Perkins Gilman wants to express with her term "proprietary family." In these families, women and children are regarded as the property of the men, and the manners of interaction are shaped precisely by this. Perkins Gilman is concerned to make clear the political impact and the social consequences of these habits, which counteract a democratic form of government. Societies that adopt a democratic form of government must have an interest in the formation of democratic habits. Understanding democracy as a way of life also includes the habits in families. She writes:

For each man to have one whole woman to cook for and wait upon him is a poor education for democracy. The boy with a servile mother, the man with a servile wife, cannot reach the sense of equal rights we need to-day. Too constant consideration of the master's tastes makes the master selfish; and the assault upon his heart direct, or through that proverbial side-avenue, the stomach, which the dependent woman needs must make when she wants anything, is bad for the man, as well as for her. (Perkins Gilman 1911: 42-3)

Perkins Gilman contrasts this plea for democratic habits with the reality of the "proprietary family" and points to the activities and habits associated with it. What kind of habit is formed by the activities of cooking and waiting under these conditions? To be economically dependent means that someone else controls the conditions for one's own existence. The economically dependent person must fulfill the entitlements by services, which can be demanded and valued. This gives rise to the hidden threat, that the material basis can be withdrawn at will. Therefore, the dependent person not only fulfills the requirements, but does so in a way that makes the withdrawal of the conditions of existence as unlikely as possible. This leads to a servile attitude and to an overfulfillment of the required activities. One classical strategy for developing an irreplaceable bonding is the activity of cooking in accordance with special requests. This deepens the feeling of power and strength of the dominant person. The activity of waiting means to be completely attuned to the other person. The dominant person 
experiences himself as the center of attention. This leads to a feeling of superiority and self-centredness, which is contrary to a democratic habit.

This dependent, subjugating form of existence generates unease in two respects. First, being existentially dependent is connected with unease. Second, unease emerges due to the more latently or more explicitly felt threat that the conditions of existence can be withdrawn because of dissatisfaction or because of pure despotism. This unease becomes a habit and is embodied in servile, waiting bodies to which timidity and inhibition are inscribed. The somatic expressions of habitualized unease also include the somatic pattern of occupying as little space as possible, as well as taking into account subtle or even open violence. ${ }^{11}$

As habit, habitualized unease also has a self-sustaining, projective force. The habitualized unease becomes part of the self-understanding and has an effect on actions, thinking, feeling and desire. This is the reason for the recognition of the structures that create unease. Habitualized unease therefore refers to a social position of involvement in the conditions that generate unease. The means needed for critical analysis, like reflective distance and modes of articulation are missing. Critical expression can develop through an impulse from outside or through a serious deterioration. Habits of unease may become intelligent, artistic habits that are selfreflexive and open to change. But habits of unease may also freeze into a routine. There seems to be no alternative, no latitude. ${ }^{12}$

This structure of the family with its property relations is in turn made possible and supported by an androcentric reality in which the masculine is the norm and everything is related to it and designed by it. In an androcentric world, humanity is identified with masculinity and other genders are marked in their function to stabilize the "human-male." ${ }^{13}$ The claim to expression and ownership emerges. Shaping and interpreting the world co-produces a proprietary relation to the world. The "proprietary family" is therefore an institution of this androcentric reality.

In her literary work, Perkins Gilman sketches paradigmatic situations facilitated by the androcentric reality and the "proprietary family." Three types of situations have been analyzed in the first part of this article. The passage of The Yellow Wallpaper shows, how the credibility and the self-expression of a dependent person can be undermined. Fiction makes obvious the immediate effects of habitualized unease mediated by androcentric and family structures.

Often, social theoretical or philosophical analysis do not reach this level of concrete precision. The double-barreled theoretical and literary self-understanding of Perkins Gilman is a strong inspiration for critical feminist theory - with the limitations mentioned above. Moreover, Perkins Gilmans contribution consists in the systematic connection between her ontological analysis (reality is androcentric), always including power-dynamics, the analysis of institutions (such as the institution of the family) and types of situations. Perkins Gilman's insights in the phenomenon of habitualized unease in relation to gender can be profitably developed further for a more general critical conception of habitualized unease. This reveals a number of important references to other theoretical lines. Two of these are briefly presented here.

The much-discussed 2007 study by Miranda Fricker, Epistemic injustice can help to understand forms of missing credibility and lack of modes to express oneself as dimensions of injustice. Fricker examines the basic knowledge-producing practice of 
communicating one's own experiences to others. This practice, which is indispensable in everyday life, is in danger of being blocked by two forms of injustice, which Fricker calls testimonial injustice and hermeneutical injustice. Testimonial injustice refers to the phenomenon of giving limited or no credibility to someone, based on prejudice. Fricker's examples are prejudices against women and against blacks. Women or blacks are given limited or no credibility in communicating certain experiences because they are women or blacks. This analysis can help to understand, why certain articulations of unease are not listened to and did not become theory-productive. Fricker describes as hermeneutical injustice the much more far-reaching phenomenon that certain experiences cannot be communicated and understood at all because the social patterns of interpretation are lacking. As an example, Fricker cites the interpretation pattern of sexual harassment. Before its social acceptance, women could hardly or not express certain experiences and could not make their injuries understandable. This concept helps to see, why unease remains often diffuse and cannot be articulated at all. In this case, other habits block the conditions of articulation.

41 Another obvious connection for the deepening and expansion of the idea of "unease as habit" is Pierre Bourdieu's concept of habitus. Like the pragmatist concept of habit, Bourdieu's habitus functions as a mediation concept, not between individual and environment in general, but between individual and society. While the pragmatist concept of habit is developed more in a context of theory of action (especially in Dewey), Bourdieu's concept of habitus belongs in a sociological context, both concepts refer to a theory of praxis. Habitus reproduces social order and becomes permanent, i.e. temporally stable and transferable. The concept of habitus can refer to social patterns of order (e.g. the habitus of a social class) as well as to actors. In the detailed study Distinction. A Social Critique of the Judgement of Taste (1984), Bourdieu examines the distinguishing power of the habitus of different classes in society. And in the study Masculine Domination, feelings of unease are inscribed in a gender-specific female habitus..$^{14}$ In contrast to the sociological concept of habitus, the concept of habit is on the one hand not limited to social classifications such as gender or class, although these play a central role, as shown. The more flexible concept of habit, on the other hand, can be used to adopt perspectives on various social dependencies. Another important difference is that the pragmatist concept of habit systematically links the dimension of reproducing social order with the dimension of change by distinguishing between habits as routines and intelligent (artistic) habits. ${ }^{15}$

Habits are mediated as social functions and habits have an immediate effect in situations. Unease as habit has a situational dimension, habitualized unease in this sense is also situational unease, in its immediate appearance. This is a first meaning of situational unease.

43 Second, unease can also arise in situations where a routine habit is disturbed. ${ }^{16}$ In Perkins Gilman's novel Herland, the protagonist Van experiences unease despite his theoretical interest. His unease emerges when his habits in dealing with women and the deviating habits in Herland are clashing against each other. Unease can arise in dealing with otherness. Some people feel unease when they enter a foreign environment, some react with unease to smells they do not know, to behaviour and sounds. Then unease can manifest itself somatically like a feeling of being disturbed, of wanting to turn away, as if the internalized good taste is violated. Such unease stabilizes conventions. Situational unease caused by disturbed routines can liberate 
restorative energies. Like unease as a mechanical routine, it is an important form of experience that endangers living democracies and therefore needs to be recognized, described, analyzed and criticized.

Third, through situational unease one can also grasp a quality in situations that does not, or only in the background, refer to habitualized unease or to disturbed routines. We can experience unease, for example, if we have the impression that someone has been treated very subtly unfairly in a situation. But such unease is not yet a "sense of injustice." ${ }^{17}$ The experience of unease is more diffuse, vague and morally open than the sense of injustice. It is first of all like a voice that speaks out and tells us: "Something is wrong. You have to find out whether it has to do with you or the circumstances. You have to find out if you don't want to allow something new or if you are suffering from something that is problematic, that should be changed."

In the following, however, I would only like to deal with one common feature of these three types of situational unease, namely their appearance of immediacy. Here, "immediacy" does not mean something personally authentic, but rather the grasping of the quality of a situation as, for example, ceremonial, dramatic, tense, released - or even uneasy. In his essay Qualitative Thought (1930), Dewey defines qualities not as properties, but as that which distinguishes one situation from others, which pervades every associated detail and gives them significance. ${ }^{18}$ Such pervasive qualities have a direction of transition that evokes articulations, for example in the form of actions or thoughts. Qualities thus "are" something in situations themselves and not projections from the subject's perspective. ${ }^{19}$ This does not mean that all persons involved must experience situations in the same way. Qualities have the function of grasping situations as a whole and orienting our actions accordingly. Qualities enable an overall impression, which is not, however, made up of distinct, specifiable individual parts, but of small aspects that cannot be disentangled. Also the grasping subject merges with this holistic, atmospheric quality and is an immanent part of it. Qualities are of the utmost importance for our understanding and actions and must be given an appropriate place in every theorization. ${ }^{20}$ Yet it is very difficult to determine them precisely in theory. Qualitative experiencing is characterized by an indeterminacy and vagueness that disappears in conceptualization. Dewey describes qualitative experiencing as a medium where distinctions such as those between active and passive, subjective and objective are undermined.

Unease or uneasiness as qualities differ from other qualities such as ceremonial, dramatic, tense, released by its negative form: un-ease. Unease has a diffuse evaluative dimension. Unease is something unpleasant, perhaps irritating, oppressive, threatening. But it is not clearly defined as negative, it remains not clearly attributable to someone or something. Perkins Gilman describes the quality of the whole situation in The Yellow Wallpaper as increasingly uneasy. This holds for the passage interpreted as for the story as a whole. In the story, the process of spreading is unfolded until those, like the husband, who want to maintain their position of sovereignty until the very end, are also involved into this unease. The Yellow Wallpaper was interpreted by some as a ghost story. In this perspective, the pervasive quality in the overall situation should be described as "horrific." ${ }^{21}$ I rather suggest to read the story differently. Perkins Gilman uses the means of fiction, to show how a woman's habitualized unease pervades an overall situation and becomes quasi-autonomous. 
47 I would like to conclude with a few remarks about the relevance of the concept of unease to democracy as a way of life. Democracies as a way of life should have an interest in developing an "uneasy-reflexive" democratic practice. I would like to relate this to habitualized unease and to one type of situational unease.

In this article, especially the habitualized unease is developed on concrete material which deals with the category of gender. At the same time, I have established a more general perspective of analysis. Habitualized unease can be related to all structures of normalization which disguise their particularity. Habitualized unease is characterized by including one's own marginalization and inferiorization in one's own selfunderstanding and thus recognizing it. Habitualized unease is therefore not a form of inhibition of articulation that could be resolved by friendly invitation. Here, too, the various waves of feminism can exemplify the long, unfinished path of generating attention, inventing new forms of articulation and forming political forces, through which long habitualized unease becomes reflexive and changeable. But processes of resolving and dissolving of habitualized unease also lead very often to the formation of something like a "counter-unease." This may be generated for those whose routine habit is disturbed. This phenomenon was mentioned above as a type of situational unease that can mobilize immense political (counter)forces. Unease is a powerful sensation in the public and in the so-called private sphere. Therefore, it is in the very interest of a democracy as a way of life to further develop the phenomenology and theory of unease.

\section{BIBLIOGRAPHY}

AHMED Sara, (2017), Living a Feminist Life, Durham, Duke University Press.

ALLEN Judith, (2004), “The Overthrow’ of Gynaecocentric Culture: Charlotte Perkins Gilman and Lester Frank Ward," in Cynthia Davis \& Denise Knight (eds.), Charlotte Perkins Gilman and Her Contemporaries, Tuscaloosa, University of Alabama Press, 59-86.

ALLEN Judith, (2009), The Feminism of Charlotte Perkins, Chicago, Chicago University Press. BOURDIEU Pierre, (1984), Distinction. A Social Critique of the Judgement of Taste, Harvard, Harvard University Press.

BOURDIEU Pierre, (2001), Masculine Domination, Stanford, Stanford University Press.

CROSSLEY Nick, (2013), “Habit and Habitus," Body \& Society, 19 (2-3), 136-61.

DAVIS Cynthia J., (2003), "His and Herland: Charlotte Perkins Gilman 'Re-presents' Lester F. Ward,” in Lois Cuddy \& Claire Roche (eds.), Evolution and Eugenics in American Literature and Culture, 1880-1940, Lewisburg, Bucknell University Press, London, Associated University Presses, 73-88. DAVIS Cynthia, (2010), Charlotte Perkins Gilman, Stanford, Stanford University Press. DEWEY John, (1922), "Human Nature and Conduct. An Introduction to Social Psychology," in The Middle Works, vol. 14, ed. by Jo Ann Boydston, Carbondale, Southern Illinois University Press. 
DEWEY John, (1929-1930), "Qualitative Thought," in The Later Works, vol. 5, ed. by Jo Ann Boydston, Carbondale, Southern Illinois University Press, 243-62.

DEWEY John, (1938), "Logic: The Theory of Inquiry," in The Later Works, vol. 12, ed. by Jo Ann Boydston, Carbondale, Southern Illinois University Press.

DÖLLING Irene \& Beate KRAIS (eds.), (2017), Ein alltägliches Spiel: Geschlechterkonstruktion in der sozialen Praxis, Frankfurt-a.-Main, Suhrkamp.

FRICKER Miranda, (2007), Epistemic Injustice. Power and the Ethics of Knowing, New York, Oxford University Press.

GROsz Elisabeth, (2013), "Habit Today: Ravaisson, Bergson, Deleuze and Us," Body \& Society, 19 (2-3), 217-39.

HADDOCK SEIGFRIED Charlene, (1991a), “The Missing Perspective: Feminist Pragmatism,” Transactions of the Charles S. Peirce Society, 27 (4), 405-16.

HADDOCK SEIGFRIED Charlene, (1991b), "Where Are All the Pragmatist Feminists?," Hypatia, 6 (2), $1-20$.

HADDOCK SEIGFRIED Charlene, (1993), "Shared Communities of Interest: Feminism and Pragmatism," Hypatia, 8 (2), 1-14.

HADDOCK SEIGFRIED Charlene, (1996), Pragmatism and Feminism: Reweaving the Social Fabric, Chicago, Chicago University Press.

HADDOCK SEIGFRIED Charlene, (2001), “Can a 'Man-hating' Feminist also be a Pragmatist? On Charlotte Perkins Gilman," Journal of Speculative Philosophy, 15 (2) (Special Issue on "Pragmatist Feminism"), 74-85.

HALl Stuart, (2017), Familiar Stranger. A Life Between Two Islands, Durham, Duke University Press. HILL Mary, (1980), Charlotte Perkins Gilman: The Making of a Radical Feminist, 1860-1896, Philadelphia, Temple University Press.

LANE Ann, (1990), To "Herland" and Beyond: The Life and Work of Charlotte Perkins Gilman, New York, Pantheon.

LOVECRAFT Howard Phillips, (2000 [1927]), "Supernatural Horror in Literature," in August Derleth (ed.), H.P. Lovecraft Omnibus 2. Dagon and Other Macabre Tales, New York, Harper-Collins, 423-6.

NEWMAN Louise Michele, (1999), White Women's Rights: The Racial Origins of Feminism in the United States, New York, Oxford University Press.

PERKINS GILMAN Charlotte, (1892), The Yellow Wallpaper, Boston, Small, Maynard \& Co.

PERKINS GILMAN Charlotte, (1898), Women and Economics: A Study of the Economic Relation Between Men and Women as a Factor in Social Evolution, Boston, Small, Maynard \& Co.

PERKINS GILMAN Charlotte, (1909/10), What Diantha Did, serialized in The Forerunner, I, nos 1-14. PERKINS GILMAN Charlotte, (1911), The Man-Made World; or, Our Androcentric Culture, New York, Charlton.

PERKINS GILMAN Charlotte, (1979 [1915]), Herland, New York, Pantheon Books.

PERKINS GILMAN Charlotte, (1999), The Yellow Wall-Paper, Herland, and Selected Writings, ed. by Denise Knight, New York, Penguin Classics. 
SALVERRÍA Heidi, (2020), "Vague Certainty, Violent Derealization, Imaginative Doubting.

Reflections on Common Sense and Critique in Peirce and Butler," European Journal of Pragmatism

and American Philosophy, XII-2.

SHKLAR Judith, (1990), The Faces of Injustice, New Haven \& London, Yale University Press.

WILLE Katrin, (2017), “Natur als Drama. Deweys Neubestimmung der Teleologie,” in Michael

Hampe (ed.), John Dewey: Erfahrung und Natur, Berlin, De Gruyter, 49-64.

YounG Iris Marion, (1980), "Throwing Like a Girl: A Phenomenology of Feminine Body

Comportment Motility and Spatiality," Human Studies, 3, 137-56.

\section{NOTES}

1. Charlene Haddock Seigfried in particular has reappropriated a historical line of pragmatist feminism and used the work of thinkers such as Ella Lyman Cabot, Jane Addams and Charlotte Perkins Gilman as a source of feminist analysis. Cf. Haddock Seigfried (1996; 1993; 1991a; 1991b); see her essay on Charlotte Perkins Gilman (Haddock Seigfried 2001).

2. Cf. Dewey (1929-1930).

3. Cf. on person and work: Davis (2010), Hill (1980), Lane (1990).

4. She developed a peculiar form of argument using social Darwinism, which is primarily intended to support her conception of gender and humanity. She argues that it would be functional for the further development of human beings if women were to make the choice to form a reproductive community, as is often the case in the animal kingdom, and not men. Therefore, the practices of dressing up and making oneself beautiful and competing with people of the same sex should actually be male practices. Women have to be the selective forces and should figure as representatives of the race-type and must bear the actual evolutionary task. Gilman attributes this idea, which she finds immensely fascinating, to the sociologist Lester F. Ward and his "gynocentric theory of life," to whom she dedicates the study The Man-Made World; or, Our Androcentric Culture. Cf. the critical analysis: Allen (2004), Davis (2003).

5. Cf. to this Newman (1999).

6. Cf. to this Allen (2009).

7. At many points in the novel, motherhood serves as a substitute for religion.

8. This is expressed very concisely right at the beginning of Stuart Hall's biographical reflection: "These changes didn't magically resolve the unease which had been incubated as I grew up in a racially subordinate position in colonial Jamaica." (Hall 2017: 3).

9. Charles Sanders Peirce introduces the term "habit" into the discussion with reference to scholastic texts. Habit is an important term for most pragmatist approaches. In the following, I refer mainly to Dewey (1922).

10. I am referring to Perkins Gilman (1898; and 1911).

11. The embodiment of habitualized unease is a very important level which must be described in detail following the investigations of theoreticians such as Iris Marion Young or Sara Ahmed. Young has analyzed feminine self-limitation with the means of phenomenology as "inhibited intentionality." In her classic and still groundbreaking study "Throwing Like a Girl," Young uses the example of throwing to show how girls learn not to execute the movement of throwing with their whole body. Ahmed describes the physical effect of the expectation of violence: "The violence does things. You begin to expect it. You learn to inhabit your body differently through this expectation. When you sense the world out there as a danger, it is your relation to your own body that changes: you become more cautious, timid. [...] Girls come to take up less space by what 
they do, and by what they do not do. Girls come to restrict themselves through restricting how they use their bodies." (Ahmed 2017: 41).

12. Perkins Gilman writes about the conditions of the proprietary family: "We are so accustomed to this relation; have held it for so long to be the natural relation, that it is difficult indeed to show it to be distinctly unnatural and injurious." (Perkins Gilman 1911: 36). And: "But it is no swift and easy matter to disabuse the race mind from attitudes and habits inculcated for a thousand years. What we have been fed upon so long we are well used to, what we are used to we like, what we like we think is good and proper." (Ibid.: 103).

13. Cf. Perkins Gilman's equation: “'mankind' meant men-kind." (Perkins Gilman 1911: 18).

14. For Bourdieu, this follows from the determination of the female being as being-perceived. E.g.: "The probability of experiencing the body with embarrassment (the form par excellence of the experience of the 'alienated body'), malaise, timidity or shame rises with the discrepancy between the socially demanded body and the practical relation to the body that is imposed by the gazes and reactions of others. It varies very strongly according to sex and position in the social space." (Bourdieu 2001: 65).

15. The considerations of Félix Ravaisson could be connected to this dimension of changeability and creativity of habit, see e.g. Grosz (2013); on the relationship between habitus and habit see also Crossley (2013).

16. Cf. "A habit, a routine habit, when interfered with generates uneasiness, sets up a protest in favor of restoration and a sense of need of some expiatory act, or else it goes off in casual reminiscence." (Dewey 1922: 54).

17. This term is developed by Shklar (1990).

18. Dewey (1929-1930). In the fourth chapter of Logic: The Theory of Inquiry Dewey elaborated this idea and its function for the initiation and control of research processes. Cf. Dewey (1938: 66-85), cf. also my paper: Wille (2017).

19. "[I]t is to be remarked that a situation is a whole in virtue of its immediately pervasive quality. When we describe it from the psychological side, we have to say that the situation as a qualitative whole is sensed or felt. [...] Stating that it is felt is wholly misleading if it gives the impression that the situation is a feeling or an emotion or anything mentalistic. On the contrary, feeling, sensation and emotion have themselves to be identified and described in terms of the immediate presence of a total qualitative situation. [...] A universe of experience is the precondition of a universe of discourse." (Dewey 1938: 73-4).

20. "[T]he immediate existence of quality, and of dominant and pervasive quality, is the background, the point of departure, and the regulative principle of all thinking. Thought which denies the existential reality of qualitative things is therefore bound to end in self-contradiction and in denying itself." (Dewey 1929-1930: 261).

21. Cf. Lovecraft (2000 [1927]).

\section{ABSTRACTS}

In this article I pursue both a systematic and a historical interest. I develop the sentiment of unease as a feminist-pragmatist concept systematically. The main references are the terms habit and situation in John Dewey and the work of Charlotte Perkins Gilman. Perkins Gilman reflects experiences of unease as a writer and as a (social) theorist. The paper is therefore also a historical appreciation of the theoretical work of Charlotte Perkins Gilman. With Perkins Gilman, 
uneasiness appears to be an expression of an androcentric world, more generally speaking, of a world in which gender relations are understood according to the pattern of normality and deviation. This can be generalized and unease can be understood as an expression of power asymmetries that damage the epistemic authority of some. Such a view is critical of a widespread tendency to individualize negative feelings and attribute them to individuals, who are then classified either as in need of individual coaching or as pathological, and who can therefore theoretically be passed over.

\section{AUTHOR}

\section{KATRIN WILLE}

Universität Hildesheim

willek[at]uni-hildesheim.de 